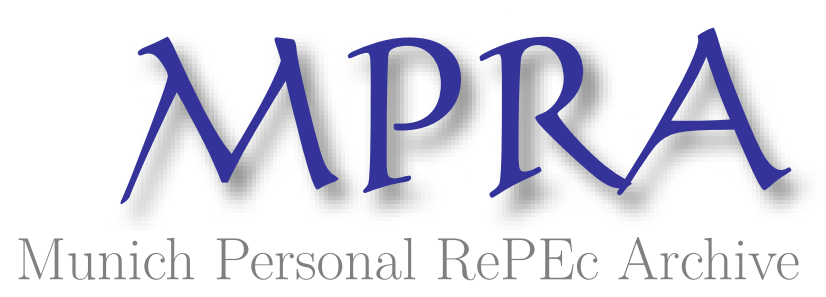

\title{
On Using Risk-Neutral Probabilities to Price Assets
}

Chang, Kuo-Ping

Jinhe Center for Economic Research, Xi'an Jiaotong University

10 November 2017

Online at https://mpra.ub.uni-muenchen.de/96564/

MPRA Paper No. 96564, posted 25 Oct 2019 13:19 UTC 


\title{
On Using Risk-Neutral Probabilities to Price Assets*
}

\author{
Kuo-Ping Chang**
}

November 2017

http://ssrn.com/abstract $=3114126$

* The author wishes to thank Professors Peter Carr and Stephen Schaefer for their helpful comments and suggestions. The usual disclaimer applies.

** Jinhe Center for Economic Research, Xi'an Jiaotong University, Xianning West Road, 28\#, Xi'an, Shaanxi Province, 710049, China; Department of Quantitative Finance, National Tsing Hua University, Kuang Fu Rd., Hsinchu 300, Taiwan. E-mail: kpchang@mx.nthu.edu.tw. 


\title{
On Using Risk-Neutral Probabilities to Price Assets
}

\begin{abstract}
This paper has used the Arbitrage Theorem under binomial case to show that in a complete market with no transaction costs and no arbitrage, for any asset, the current spot price is a function of the risk-free interest rate, the future possible prices and their probabilities. These probabilities are the actual world probabilities, not the so-called risk-neutral probabilities. The paper also proves that for the levered firm, (i) under riskless debt, increasing the debt-equity ratio increases the variance of the rate of return on equity and has no effect on the rate of return on debt; and (ii) under risky debt, increasing the debt-equity ratio increases the variance of the rate of return on debt but does not affect the probability density function of the rate of return on equity. With the actual world probabilities, it can be shown that changes in the debt-equity ratio do not affect the expected rate of return on the equity of the levered firm. These findings refute the Modigliani-Miller second proposition that the expected rate of return on the equity of the levered firm increases in proportion to the debt-equity ratio. With the actual world probabilities, it is also found that increasing the variance of the underlying asset price may either increase or decrease the option prices.
\end{abstract}

Keywords: The Arbitrage Theorem, risk-neutral probabilities, capital structure irrelevancy.

JEL Classification: G13, G32. 
"Our expectations for the future will determine our current behavior."

\section{Introduction}

The seminal work of Modigliani and Miller (1958) has presented the Modigliani-Miller second proposition: in the levered firm, "a premium related to financial risk equal to the debt-to-equity ratio times the spread between $\rho_{k}$ (the expected rate of return on the firm's total assets) and $r$ (the expected rate of return on the debt)" (p. 271). The corporate finance literature emphasizes that because increasing the debt-equity ratio increases risk to equity-holders, the expected rate of return on the equity of the levered firm increases in proportion to the debt-equity ratio. Cox, Ross and Rubinstein (1979) argue that their binomial option model does not use probabilities to calculate option prices, and the probabilities used are the risk-neutral probabilities, not the actual world probabilities.

Unfortunately, both the Modigliani-Miller second proposition and Cox et al.'s arguments are not correct. In this paper, I use the Arbitrage Theorem under binomial case to show that in a complete market with no transaction costs and no arbitrage, for any asset, the current spot price is a function of the risk-free interest rate, the future possible prices and their probabilities. These probabilities are the actual world probabilities, not the so-called risk-neutral probabilities. The paper also proves that for the levered firm, (i) under riskless debt, increasing the debt-equity ratio increases the variance of the rate of return on equity and has no effect on the rate of return on debt; and (ii) under risky debt, increasing the debt-equity ratio increases the variance of the rate of return on debt but does not affect the probability density function of the rate of return on equity. With the actual world probabilities, it can be shown that changes in the debt-equity ratio do not affect the expected rate of return on the equity of the levered firm. It is also found that increasing the variance of the underlying asset price may either increase or decrease the option prices.

The remainder of this paper is organized as follows. Section 2 uses the Arbitrage Theorem under the binomial case to show that the current spot price is a function of the risk-free interest rate, the future possible prices and their probabilities. Once the risk-free interest rate, the current spot price, and the future possible prices are assumed, the probabilities will be determined. Section 3 shows that the probabilities used in the binomial option pricing model are the actual world probabilities. Section 4 clarifies the errors in the literature and proves two capital structure irrelevancy propositions. Concluding remarks appear in Section 5. 


\section{Implications of the Arbitrage Theorem}

In the corporate finance literature, the following example is used to explain the Modigliani-Miller second proposition: ${ }^{1}$

A totally equity-financed firm's assets are $\$ 8,000$. The firm is considering issuing riskless debt to buy half of the equity, i.e., $\$ 4,000$. The risk-free interest rate is 10 percent. There are two states of nature: expansion and recession, and each has probability 0.5 . The outcomes under alternative capital structures are shown in Table 1.

Table 1. Outcomes under alternative capital structures.

\begin{tabular}{|c|c|c|c|c|c|c|}
\hline & \multicolumn{3}{|c|}{ No debt } & \multicolumn{3}{|c|}{ With debt } \\
\hline & Recession & Expected & Expansion & Recession & Expected & Expansion \\
\hline $\begin{array}{l}\text { Rate of Return } \\
\text { on assets }\end{array}$ & $5 \%$ & $15 \%$ & $25 \%$ & $5 \%$ & $15 \%$ & $25 \%$ \\
\hline $\begin{array}{l}\text { Earnings before } \\
\text { Interest }\end{array}$ & $\$ 400$ & $\$ 1,200$ & $\$ 2,000$ & $\$ 400$ & $\$ 1,200$ & $\$ 2,000$ \\
\hline Interest & 0 & 0 & 0 & $\$ 400$ & $\$ 400$ & $\$ 400$ \\
\hline $\begin{array}{l}\text { Earnings after } \\
\text { Interest }\end{array}$ & $\$ 400$ & $\$ 1,200$ & $\$ 2,000$ & 0 & $\$ 800$ & $\$ 1,600$ \\
\hline $\begin{array}{l}\text { Rate of return } \\
\text { on equity }\end{array}$ & $5 \%$ & $15 \%$ & $25 \%$ & $0 \%$ & $20 \%$ & $40 \%$ \\
\hline
\end{tabular}

After replacing half of the firm's equity with debt, the expected rate of return on equity increases

${ }^{1}$ E.g., see Ross, Westerfield, Jaffe and Jordan (2016, Chapter 16) or Brealey, Myers and Allen (2017, Chapter 17). 
from $15 \%$ to $20 \%$. Based on this kind of analysis, it is argued that "the use of debt rather than equity funds to finance a given venture may well increase the expected return to the owners, but only at the cost of increased dispersion of the outcomes" (Modigliani and Miller, 1958, p. 262); and "any gains from using more of what might seem to be cheaper debt capital would thus be offset by correspondingly higher cost of the now riskier equity capital” (Miller, 1988, p. 100).

Unfortunately, the above example is erroneous. To see this let us rewrite Table 1's continuous-time example as a one-period binomial example:

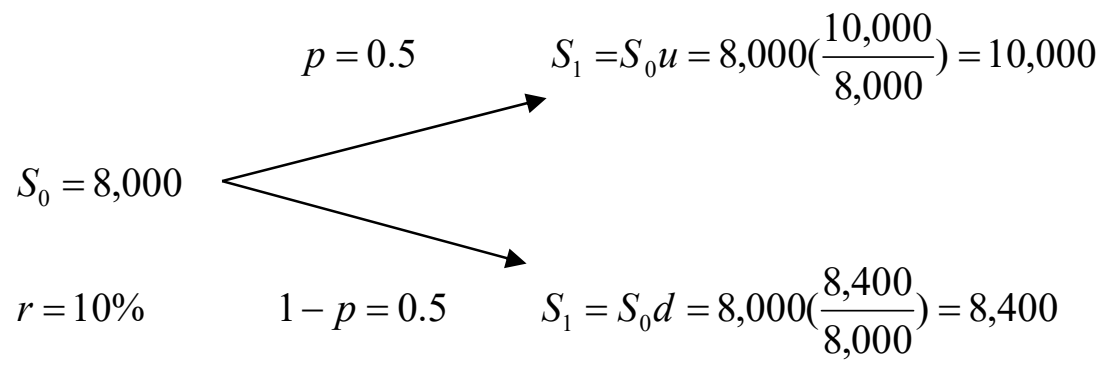

Figure 1. An erroneous binomial model.

That is, in addition to assuming risk-free interest rate: $r=10 \%$, current spot price: $S_{0}=8,000$, future possible prices: $S_{0} u=10,000$ and $S_{0} d=8,400$ and their probabilities: $p=0.5$ and $1-p=0.5$ are also assumed. This is erroneous because current spot price is determined by risk-free interest rate, future possible prices and their probabilities, i.e., among the five variables: $r, S_{0}, S_{0} u, S_{0} d$, and $p$, only four of them can be freely assumed (or the degree of freedom is only four, not five). For example, if $r=10 \%$ and a bank promises a future payoff: $S_{1}=110$ with probability one: $p=1$, the current deposit asked by the bank must be: $S_{0}=S_{1} /(1+r)=100$. If the current spot price of an asset is $S_{0}=100, r=10 \%$, no default: $p=1$ and no storage cost, the forward price of this asset must be $S_{1}=(1+r) S_{0}=110$. Suppose that in Figure 1, one of the four variables: $r, S_{0}, S_{0} u, S_{0} d$ changes: 


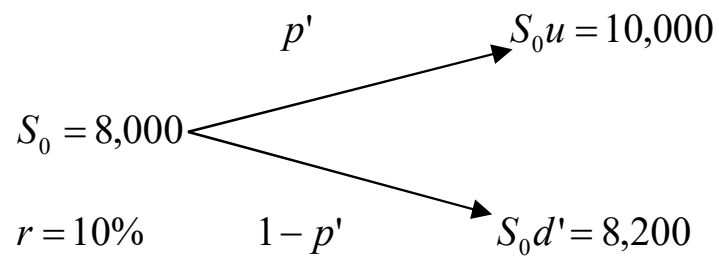

(a)

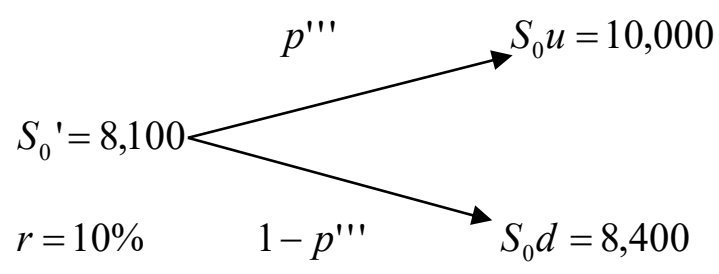

(c)

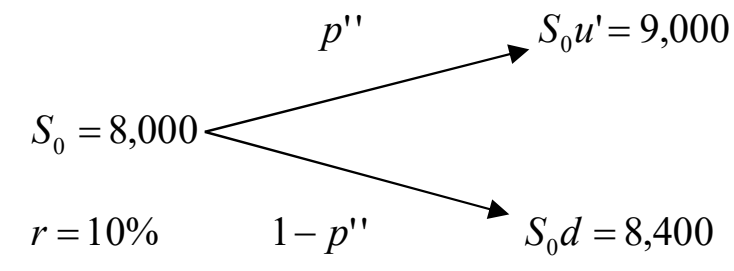

(b)

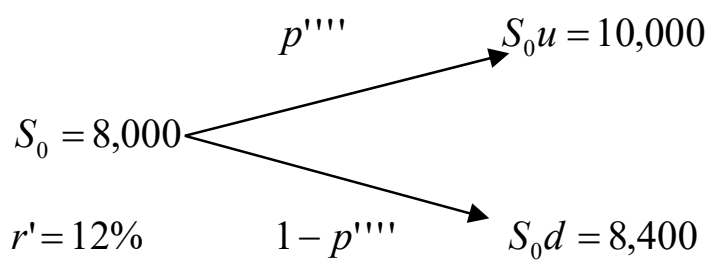

(d)

Figure 2. Changes of probabilities.

Case (a): $p^{\prime}$ must be greater than $p$ of Figure 1. This is because when $S_{0} u$ and $r$ remain the same, and $S_{0} d=8,400$ decreases to $S_{0} d^{\prime}=8,200$, the current stock price $S_{0}$ can remain the same only when investors (the market) believe the probability of the up move $S_{0} u$ is higher than before.

Case (b): $p^{\prime \prime}$ must be greater than $p$ of Figure 1 because when $S_{0} d$ and $r$ remain the same, and $S_{0} u=10,000$ decreases to $S_{0} u^{\prime}=9,000$, the current stock price $S_{0}$ can remain the same only when investors (the market) believe the probability of the up move $S_{0} u^{\prime}$ is higher than before.

Case (c): $p^{\prime \prime \prime}$ must be greater than $p$ of Figure 1 because when $S_{0} u, S_{0} d$, and $r$ remain the same, and $S_{0}$ can increase from 8,000 to 8,100 , this is possible only when investors (the market) believe the probability of the up move $S_{0} u$ is higher than before.

Case (d): $p^{\prime \prime \prime \prime}$ must be greater than $p$ of Figure 1 because when $S_{0} u$ and $S_{0} d$ remain the same, and $r$ increases from $10 \%$ to $12 \%$, the current stock price $S_{0}$ can remain the same only when investors 
(the market) believe the probability of the up move $S_{0} u$ is higher than before.

These results show that in the binomial case, the five variables: $r, S_{0}, S_{0} u, S_{0} d, p$ are closely related, and the degree of freedom is four, not five.

The following theorem proves that the current spot price $S_{0}$ is a function of $r, S_{0} u, S_{0} d$, and $p .^{2}$ Gordan Theorem (the Arbitrage Theorem):

Let $\mathbf{A}$ be an $m \times n$ matrix. Then, exactly one of the following systems has a solution:

System 1: $\quad \mathbf{A x}>\mathbf{0} \quad$ for some $\mathbf{x} \in R^{n}$

System 2: $\quad \mathbf{A}^{t} \mathbf{p}=\mathbf{0} \quad$ for some $\mathbf{p} \in R^{m}, \mathbf{p} \geq \mathbf{0}, \mathbf{e}^{t} \mathbf{p}=1$ where $\mathbf{e}=\left[\begin{array}{l}1 \\ 1 \\ . \\ 1\end{array}\right]$

In System 2 of the Arbitrage Theorem, the vector $\mathbf{p}$ is a probability measure, and $p_{i}, i=1, \ldots, m$, can be interpreted as the current price of one dollar received at the end of period if state $i$ occurs. If System 2 holds and the matrix $\mathbf{A}$ has rank $m-1$ (i.e., the matrix has $m-1$ independent rows), the probability measure $\mathbf{p}$ will be unique. ${ }^{3}$

In the above example (Figure 1), with no arbitrage, i.e., System 2 holds, the probability of the up move, $p$, is equal to $\frac{1}{4}$ rather than 0.5 :

$$
\left[\begin{array}{ll}
1.1-1(1+0.1) & 1.1-1(1+0.1) \\
10,000-8,000(1+0.1) & 8,400-8,000(1+0.1)
\end{array}\right]\left[\begin{array}{l}
1 / 4 \\
3 / 4
\end{array}\right]=\left[\begin{array}{l}
0 \\
0
\end{array}\right] \text {, }
$$

or

\footnotetext{
${ }^{2}$ See Chang (2015, p. 41).

${ }_{3} \mathbf{A}^{t} \mathbf{p}=\mathbf{0}$ and $\mathbf{p}$ is a non-zero vector imply the rank of $\mathbf{A}^{t}, R\left(\mathbf{A}^{t}\right)$, is less than $m$. Unique solution for $\left(p_{1}, \ldots, p_{m}\right)$ and $\sum_{i=1}^{m} p_{i}=1$ imply $R\left(\mathbf{A}^{t}\right)=m-1$.
} 


$$
\left\{\begin{array}{l}
\text { Money Market (Security 1) : } S_{0}^{1}=1=\frac{1}{1+r}\left[p \cdot S_{0}^{1} u+(1-p) \cdot S_{0}^{1} d\right]=\frac{1}{1+0.1}\left(\frac{1}{4} \times 1.1+\frac{3}{4} \times 1.1\right) \\
\text { The Firm (Security 2): } S_{0}^{2}=8,000=\frac{1}{1+r}\left[p \cdot S_{0}^{2} u+(1-p) \cdot S_{0}^{2} d\right]=\frac{1}{1+0.1}\left(\frac{1}{4} \times 10,000+\frac{3}{4} \times 8,400\right)
\end{array} .\right.
$$

The above matrix $\mathbf{A}^{t}$ has $m-1=2-1=1$ independent column which means a complete market, i.e., every asset can be replicated by other $m=2$ assets. $^{4}$

The probabilities in Figure 2 can be calculated from the equation:

$$
S_{0}=\frac{1}{1+r}\left[p \cdot S_{0} u+(1-p) \cdot S_{0} d\right], \text { and } p=\frac{(1+r)-d}{u-d}, 1-p=\frac{u-(1+r)}{u-d} .
$$

Case (a): when $S_{0}^{2} d=8,400$ decreases to $S_{0}^{2} d^{\prime}=8,200, p^{\prime}=\frac{1.1-1.025}{1.25-1.025}=\frac{1}{3}>p=\frac{1.1-1.05}{1.25-1.05}=\frac{1}{4}$.

Case (b): when $S_{0}^{2} u=10,000$ decreases to $S_{0}^{2} u^{\prime}=9,000, \quad p^{\prime \prime}=\frac{1.1-1.05}{1.125-1.05}=\frac{2}{3}>p=\frac{1}{4}$.

Case (c): when $S_{0}^{2}=8,000$ increases to $S_{0}^{2}=8,100, p^{\prime \prime \prime}=\frac{1.1-8,400 / 8100}{10,000 / 8,100-8,400 / 8100}=\frac{51}{160}>p=\frac{1}{4}$.

Case (d): when $r=10 \%$ increases to $r^{\prime}=12 \%, p^{\prime \prime \prime \prime}=\frac{1.12-1.05}{1.25-1.05}=\frac{7}{20}>p=\frac{1}{4}$.

From equation (2), we can derive the following properties of the probability $p$ :

${ }^{4}$ Riskless asset's future payoff vector: $\left[\begin{array}{l}1.1 \\ 1.1\end{array}\right]$ and risky asset's future payoff vector: $\left[\begin{array}{l}10,000 \\ 8,400\end{array}\right]$ are linearly independent and hence, can replicate any other asset $d$ 's future payoff vector: $\left[\begin{array}{l}8 \\ 4\end{array}\right]$, where $\left[\begin{array}{l}8 \\ 4\end{array}\right]=\left[\begin{array}{l}1.1 \\ 1.1\end{array}\right] \cdot\left(\frac{-170}{11}\right)+\left[\begin{array}{l}10,000 \\ 8,400\end{array}\right] \cdot\left(\frac{1}{400}\right)$, and asset $d$ 's current $\quad$ spot $\quad$ price $\quad$ is: $\quad \frac{50}{11}=1 \cdot\left(\frac{-170}{11}\right)+8,000 \cdot\left(\frac{1}{400}\right) \quad=\frac{1}{1+0.1}\left(\frac{1}{4} \cdot 8+\frac{3}{4} \cdot 4\right) \quad$. By $\quad$ System $\quad 2$, $\mathbf{A}^{t} \mathbf{p}=\left[\begin{array}{ll}1.1-1(1+0.1) & 1.1-1(1+0.1) \\ 10,000-8,000(1+0.1) & 8,400-8,000(1+0.1) \\ 8-(50 / 11)(1+0.1) & 4-(50 / 11)(1+0.1)\end{array}\right]\left[\begin{array}{l}1 / 4 \\ 3 / 4\end{array}\right]=\left[\begin{array}{l}0 \\ 0 \\ 0\end{array}\right]$, where $\left[\begin{array}{l}1.1 \\ 10,000 \\ 8\end{array}\right]$ and $\left[\begin{array}{l}1.1 \\ 8,400 \\ 4\end{array}\right]$ are linearly independent. Since $\quad\left[\begin{array}{l}1(1+0.1) \\ 8,000(1+0.1) \\ (50 / 11)(1+0.1)\end{array}\right] \quad$ is $\quad$ a convex $\quad$ combination $\quad$ of $\quad\left[\begin{array}{l}1.1 \\ 10,000 \\ 8\end{array}\right]$ and $\left[\begin{array}{l}1.1 \\ 8,400 \\ 4\end{array}\right]$, i.e., $\left[\begin{array}{l}1(1+0.1) \\ 8,000(1+0.1) \\ (50 / 11)(1+0.1)\end{array}\right]=\left[\begin{array}{l}1.1 \\ 10,000 \\ 8\end{array}\right] \cdot\left(\frac{1}{4}\right)+\left[\begin{array}{l}1.1 \\ 8,400 \\ 4\end{array}\right] \cdot\left(\frac{3}{4}\right),\left[\begin{array}{l}1.1-1(1+0.1) \\ 10,000-8,000(1+0.1) \\ 8-(50 / 11)(1+0.1)\end{array}\right]$ and $\left[\begin{array}{l}1.1-1(1+0.1) \\ 8,400-8,000(1+0.1) \\ 4-(50 / 11)(1+0.1)\end{array}\right]$ are linearly dependent, i.e., $R\left(\mathbf{A}^{t}\right)=m-1=1$. 


$$
\frac{\partial p}{\partial u}<0, \frac{\partial p}{\partial d}<0, \frac{\partial p}{\partial r}>0 \text {, and } \frac{\partial p}{\partial S_{0}}>0 \text { (where } r, S_{0} u \text {, and } S_{0} d \text { remain constant). }
$$

Among the five variables: $r, S_{0}, S_{0} u, S_{0} d$, and $p$, only four of them can be freely assumed, i.e., the degree of freedom is only four, not five.

\section{There Is No Such Thing as Risk-Neutral Probabilities}

Suppose that in the Figure 1 case, the firm issues a European call option $C$ with strike price $K=\$ 8,900$, and a European put option $P$ with strike price $K=\$ 8,900$.

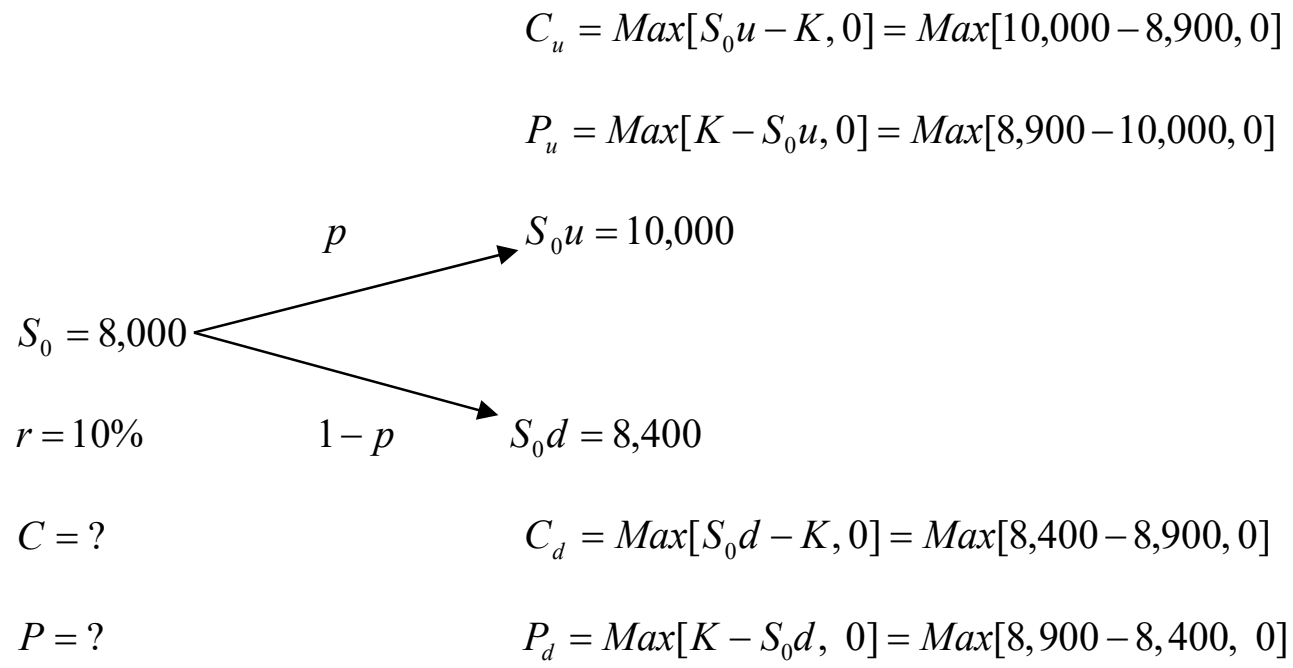

Figure 3. A binomial option pricing model.

To calculate $C$, in the beginning of the period $t=0$, forming the levered hedge strategy: (1) sell 16/11 calls, (2) buy the firm at $\$ 8,000$, and (3) borrow $\$ 84,000 / 11$ at $10 \%$. At the end of the period $t=T$, as shown in Table 2, this hedge strategy gives zero payoff at each state. 
Table 2. Zero investment at $t=0$ gives zero payoff at $t=T$.

\begin{tabular}{lccc}
\hline & $t=0$ & \multicolumn{2}{c}{$t=T$} \\
& & $S_{1}=\$ 10,000$ & $S_{1}=\$ 8,400$ \\
Sell $\frac{16}{11}$ calls & $\frac{16}{11} C$ & $-1,600$ & 0 \\
Buy the firm & $-8,000$ & 10,000 & 8,400 \\
Borrow & $\frac{84,000}{11}$ & $-8,400$ & $-8,400$ \\
Total & 0 & 0 & 0 \\
\hline
\end{tabular}

That is, $\frac{16}{11} C-8,000+\frac{84,000}{11}=0$ implies $C=250$. We can also form a portfolio by buying $n$ units of the firm and borrowing $B$ to replicate the call's future payoff at $t=T$ :

$$
\left\{\begin{array}{l}
n \cdot S_{0} u-(1+r) B=C_{u}=1,100 \\
n \cdot S_{0} d-(1+r) B=C_{d}=0
\end{array}\right.
$$

where

$$
n=\frac{C_{u}-C_{d}}{S_{0} u-S_{0} d}=0.6875, \text { and } B=\frac{-1}{1+r}\left[C_{u}-n \cdot S_{0} u\right]=\frac{-1}{1+r}\left[\frac{u \cdot C_{d}-d \cdot C_{u}}{u-d}\right]=5,250,
$$

and with no arbitrage,

$$
\begin{aligned}
C & =n \cdot S_{0}-B \\
& =\frac{1}{1+r}\left[\frac{(1+r)-d}{u-d} \cdot C_{u}+\frac{u-(1+r)}{u-d} C_{d}\right]=\frac{1}{1+r}\left[p C_{u}+(1-p) C_{d}\right]=250
\end{aligned}
$$

\footnotetext{
${ }^{5}$ Alternatively, at $t=0$, we can buy $n$ units of the firm and sell one call to construct a portfolio which gives a certain future payoff at $t=T$, and $\left\{\begin{array}{l}10,000(n)-1,100=8,400(n)-0 \Rightarrow n=\frac{11}{16} \\ \frac{8,400(11 / 16)}{1+0.1}=8,000(11 / 16)-C \Rightarrow C=250\end{array}\right.$. That is, $n \cdot S_{0} u-C_{u}=n \cdot S_{0} d-C_{d} \Rightarrow n=\frac{C_{u}-C_{d}}{S_{0} u-S_{0} d}$, and hence,
} 
Cox, Ross and Rubinstein (1979) argue that in Table 2, "all we needed to determine the exact value of the call was its striking price, underlying asset price, range of movement in the underlying asset price, and the rate of interest. What may seem more incredible is what we do not need to know: among other things, we do not need to know the probability that the underlying asset price will rise or fall" (p. 232). Cox et al. also argue that in the risk-neutral world, the expected rate of return on the underlying asset would be the riskless interest rate:

$$
q\left(S_{0} u\right)+(1-q)\left(S_{0} d\right)=(1+r) S_{0}
$$

and

$$
q=\frac{(1+r)-d}{u-d}=p
$$

thus, “ $p$ is the value $q$ would have in equilibrium if investors were risk-neutral ... hence, the value of the call can be interpreted as the expectation of its discounted future value in a risk-neutral world" (p. 235).

Unfortunately, Cox et al.'s arguments are not correct. First, as shown in equations (2) and (3), $S_{0}$ is a function of $r, S_{0} u, S_{0} d$ and $p$, and the degree of freedom is four, not five. That is, investors' preferences and risk attitudes (expectations) are incorporated into $r, S_{0} u, S_{0} d$, and $p$, which in turn determine the current spot price $S_{0}$. Also, once $S_{0}, r, S_{0} u$, and $S_{0} d$ are assumed, $p$ of eq. (2) (or $q$ of eq. (5)) will be determined, and $q$ and $(1-q)$ are the actual world's (subjective) probabilities: $p$ and $(1-p)$, not the so-called risk-neutral probabilities. ${ }^{6}$

$\left[S_{0} u \cdot \frac{C_{u}-C_{d}}{S_{0}(u-d)}-C_{u}\right] /(1+r)=S_{0} \cdot \frac{C_{u}-C_{d}}{S_{0}(u-d)}-C \Rightarrow C=\left[p C_{u}+(1-p) C_{d}\right] /(1+r)$, where $p=\frac{(1+r)-d}{u-d}, 1-p=\frac{u-(1+r)}{u-d}$.

${ }^{6}$ In equation (2), we implicitly use the money market account as numeraire. We can also use the firm account as numeraire, i.e., a change of measure. That is, from $p=\frac{(1+r)-d}{u-d}$ and $1-p=\frac{u-(1+r)}{u-d}$, we have $1=p+(1-p)=(1+r)\left[p \cdot \frac{u}{1+r} \cdot \frac{1}{u}+(1-p) \cdot \frac{d}{1+r} \cdot \frac{1}{d}\right]$. Divide both sides of the equation by $S_{0}, \quad$ we have $\frac{1}{S_{0}}=(1+r)\left[p \cdot \frac{u}{1+r} \cdot \frac{1}{S_{0} u}+(1-p) \cdot \frac{d}{1+r} \cdot \frac{1}{S_{0} d}\right]=(1+r)\left[\frac{q^{*}}{S_{0} u}+\frac{\left(1-q^{*}\right)}{S_{0} d}\right] \quad$ or $\quad\left(\frac{1}{1+r}\right) \frac{1}{S_{0}}=\frac{q^{*}}{S_{0} u}+\frac{\left(1-q^{*}\right)}{S_{0} d} \quad, \quad$ where 
Second, with no arbitrage (i.e., System 2 of the Arbitrage Theorem holds), for Figure 3 we have:

$$
\left\{\begin{array}{ll}
\text { Money Market: } & 1=\frac{1}{1+r}[p(1+r)+(1-p)(1+r)]=\frac{1}{1+0.1}\left[\frac{1}{4} \times 1.1+\frac{3}{4} 1.1\right] \\
\text { The Firm: } & S_{0}=8,000=\frac{1}{1+r}\left[p \cdot S_{0} u+(1-p) \cdot S_{0} d\right]=\frac{1}{1+0.1}\left[\frac{1}{4} \times 10,000+\frac{3}{4} \times 8,400\right] \\
\text { Call Option: } & C=250=\frac{1}{1+r}\left[p \cdot\left(S_{0} u-K\right)+(1-p) \cdot 0\right]=\frac{1}{1+0.1}\left[\frac{1}{4} \times 1,100+\frac{3}{4} \times 0\right] \\
\text { Put Option: } & P=\frac{3,750}{11}=\frac{1}{1+r}\left[p \cdot 0+(1-p)\left(K-S_{0} d\right)\right]=\frac{1}{1+0.1}\left[\frac{1}{4} \times 0+\frac{3}{4} \times 500\right]
\end{array} .\right.
$$

Suppose that in eq. (6), $S_{0} d=8,400$ decreases to $S_{0} d^{\prime}=8,200$. Then, because $p=1 / 4$ increases to $p^{\prime}=1 / 3, C=250$ will increase to $C^{\prime}=1,000 / 3$, and $P=3,750 / 11$ will increase to $P^{\prime}=14,000 / 33$. That is, $\frac{\partial p}{\partial d}<0$ leads to $\frac{\partial C}{\partial d}<0$ and $\frac{\partial P}{\partial d}<0 \cdot{ }^{7}$ Eq. (6) shows: when $S_{0}, r, S_{0} u$, and $S_{0} d$ are given, probabilities $p$ and $1-p$ will be determined, and $p, r, S_{0} u, S_{0} d$, and $K$ will determine the option prices $C$ and $P$. There is no such thing as: "the option pricing formula does not involve the probabilities of the underlying asset price moving up or down. For example, we get the same option price when the probability of an upward movement is either 0.5 or 0.9.". 8

$q^{*}=\frac{(1+r)-d}{u-d} \cdot \frac{u}{1+r}>0$ and $1-q^{*}=\frac{u-(1+r)}{u-d} \cdot \frac{d}{1+r}>0$. Properties of equation (3) still hold: $\frac{\partial q^{*}}{\partial u}<0, \frac{\partial q^{*}}{\partial d}<0$, $\frac{\partial q^{*}}{\partial r}>0$, and $\frac{\partial q^{*}}{\partial S_{0}}>0$ (where $r, S_{0} u$, and $S_{0} d$ remain constant).

7 These are the Greeks. We can also prove that $\frac{\partial C}{\partial d}=\frac{\partial P}{\partial d}<0$. For more discussions of the Greeks under the binomial distribution case and the model-free (distribution-free) case, see Chang's (2015) Chapters 4 and 5. Also, if we use the firm as numeraire, then $C=\frac{1}{1+r}\left[p \cdot\left(S_{0} u-K\right)\right]=\left[\left(p \cdot \frac{u}{1+r}\right) \frac{1}{u}\right]\left(S_{0} u-K\right)=\frac{q^{*}}{u} \cdot\left(S_{0} u-K\right)$, or $\frac{C}{S_{0}}=q^{*} \cdot \frac{S_{0} u-K}{S_{0} u}$. We have: $\frac{\partial q^{*}}{\partial d}<0$ leads to $\frac{\partial C}{\partial d}<0$. 


\section{Some Applications: New Capital Structure Irrelevancy Propositions, and Volatility and Options}

From equation (6), we can derive:

$$
\begin{aligned}
S_{0}+P & =\frac{1}{1+r}\left[p \cdot S_{0} u+(1-p) \cdot S_{0} d\right]+\frac{1}{1+r}\left[(1-p)\left(K-S_{0} d\right)\right]=\frac{1}{1+r}\left[p \cdot\left(S_{0} u-K\right)\right]+\frac{K}{1+r} \\
& =C+\frac{K}{1+r} .
\end{aligned}
$$

That is, the binomial option pricing model satisfies the put-call parity. Rearrange equation (7):

$$
S_{0}=C+\left(\frac{K}{1+r}-P\right)
$$

where $S_{0}$ can be interpreted as the market value of the levered firm, $C$ as the equity of the firm, and $\left(\frac{K}{1+r}-P\right)$ as the risky debt of the firm. In the case of riskless debt, $P=0$ and

$$
S_{0}=C+\frac{K}{1+r}
$$

where $\frac{K}{1+r}$ is the riskless debt. At $t=T$, if the equity-holders pay $K$ to the debtholders, then the equity-holders can have the firm, $S_{1}{ }^{9}$ Chang (2016) has shown that with Figure 3, we have:

(i) Under riskless debt (i.e., $K \leq S_{0} d=\$ 8,400$ ) where $d<1+r<u$.

At $t=T$, rate of return on equity at the good time is: $\frac{S_{0} u-K}{C}=\frac{S_{0} u-K}{S_{0}-\frac{K}{1+r}}=(1+r) \cdot \frac{S_{0} u-K}{S_{0}(1+r)-K}$, and higher $K$ means higher $\frac{S_{0} u-K}{C}$.

At $t=T$, rate of return on equity at the bad time is: $\frac{S_{0} d-K}{C}=\frac{S_{0} d-K}{S_{0}-\frac{K}{1+r}}=(1+r) \cdot \frac{S_{0} d-K}{S_{0}(1+r)-K}$, and higher $K$ means lower $\frac{S_{0} d-K}{C}$.

${ }^{8}$ See Appendix for more discussions on the erroneous arguments in the literature.

9 Chang $(2015$, p. 26) shows that the Modigliani-Miller First Proposition is a corollary of the put-call parity. Capital Structure Irrelevancy Proposition I should be written as: In a complete market with no transaction costs and no arbitrage, the market 


$$
t=0
$$

$K \quad$ Debt: $\frac{K}{1+r} \quad$ Equity: $C=S_{0}-\frac{K}{1+r}$

$0 \quad 0$

$100 \quad 90.9090$

7909.0910

$200 \quad 181.8182$

7818.1818

545.4545

454.5455

$8400 \quad 7636.3636$

8000

$8200 \quad 7454.5455$

$8300 \quad 7545.4545$

363.6364
$t=T$

Rate of return on debt Rate of return on equity

good time: $\frac{10000}{8000}=1.25$

bad time: $\frac{8400}{8000}=1.05$

$\left\{\begin{array}{l}\text { good time: } \frac{9900}{7909.0910}=1.2517 \\ \text { bad time: } \frac{8300}{7909.0910}=1.0494\end{array}\right.$

$\left\{\begin{array}{l}\text { good time: } \frac{9800}{7818.1818}=1.2535 \\ \text { bad time: } \frac{8200}{7818.1818}=1.0488\end{array}\right.$

$\left\{\right.$ good time: $\frac{1800}{545.4545}=3.30$

1.1

bad time: $\frac{200}{545.4545}=0.3667$

$\left\{\begin{array}{l}\text { good time: } \frac{1700}{454.5455}=3.74 \\ \text { bad time: } \frac{100}{454.5455}=0.22\end{array}\right.$

good time: $\frac{1600}{363.6364}=4.4$

1.1

value of the firm is independent of its capital structure. 
(ii) Under risky debt (i.e., $K>S_{0} d=\$ 8,400$ ).

At $t=T$, rate of return on equity at the good time is a constant: $\frac{S_{0} u-K}{C}=\frac{S_{0} u-K}{\frac{1}{1+r}\left[p\left(S_{0} u-K\right)\right]}=\frac{1+r}{p}$; and rate of return on equity at the bad time is zero: $\frac{0}{C}=0$. That is, changes in the debt-equity ratio (i.e., changes in $K$ ) have no effect on the rate of return on equity.

At $t=T$, rate of return on debt at the good time is:

$\frac{K}{S_{0}-C}=\frac{K}{\frac{1}{1+r}\left[p \cdot S_{0} u+(1-p) S_{0} d\right]-\frac{1}{1+r}\left[p\left(S_{0} u-K\right)\right]}=\frac{1+r}{p+(1-p) \frac{S_{0} d}{K}} \quad$, and higher $K$ means higher $\frac{K}{S_{0}-C}$.

At $t=T$, rate of return on debt at the bad time is: $\frac{S_{0} d}{S_{0}-C}=\frac{S_{0} d}{S_{0}-\frac{1}{1+r}\left[p\left(S_{0} u-K\right)\right]}$, and higher $K$ means lower $C$ and lower $\frac{S_{0} d}{S_{0}-C}$.

$$
t=0
$$

$K \quad$ Debt: $S_{0}-C \quad$ Equity: $C$

$=\frac{p\left(S_{0} u-K\right)}{1+r}$

$8500 \quad 7659.0909 \quad 340.9091$

$8600 \quad 7681.8182 \quad 318.1818$
$t=T$

Rate of return on debt

Rate of return on equity $\left\{\begin{array}{l}\text { good time: } \frac{8500}{7659.0909}=1.1098 \\ \text { bad time: } \frac{8400}{7659.0909}=1.0967\end{array} \quad\left\{\begin{array}{l}\text { good time: } 4.4 \\ \text { bad time: } 0.0\end{array}\right.\right.$ $\left\{\begin{array}{l}\text { good time: } \frac{8600}{7681.8181}=1.1195 \\ \text { bad time: } \frac{8400}{7681.8181}=1.0935\end{array} \quad\left\{\begin{array}{l}\text { good time: } 4.4 \\ \text { bad time: } 0.0\end{array}\right.\right.$ 


$\begin{array}{lll}8800 \quad 7727.2727 & \left\{\begin{array}{l}\text { good time: } \frac{8800}{7727.2727}=1.1388 \\ \text { bad time: } \frac{8400}{7727.2727}=1.0871\end{array} \quad \begin{array}{l}\text { good time: } 4.4 \\ \text { bad time: } 0.0\end{array}\right. \\ 8900 \quad 7750 & \left\{\begin{array}{l}\text { good time: } \frac{8900}{7750}=1.1484 \\ \text { bad time: } \frac{8400}{7750}=1.0839\end{array} \quad\left\{\begin{array}{l}\text { good time: } 4.4 \\ \text { bad time: } 0.0\end{array}\right.\right. \\ 10000 \quad 0000 & \left\{\begin{array}{l}\text { good time: } \frac{10000}{8000}=1.25 \\ \text { bad time: } \frac{8400}{8000}=1.05\end{array}\right.\end{array}$

In summary, we now have a new capital structure irrelevancy proposition:

\section{Capital Structure Irrelevancy Proposition II}

In a complete market with no transaction costs and no arbitrage, (i) under riskless debt, increasing the debt-equity ratio increases the variance of the rate of return on equity and has no effect on the rate of return on debt; and (ii) under risky debt, increasing the debt-equity ratio increases the variance of the rate of return on debt but does not affect the probability density function of the rate of return on equity.

From eq. (6) with the actual probabilities $p$ and $1-p$, we know that every asset's expected rate of return is equal to the risk-free interest rate $r$. The above proposition can be rewritten as:

\section{Capital Structure Irrelevancy Proposition II'}

In a complete market with no transaction costs and no arbitrage, changes in the debt-equity ratio do not affect the expected rate of return on the equity of the levered firm. 
These two propositions refute the Modigliani-Miller second proposition that "the use of debt rather than equity funds to finance a given venture may well increase the expected return to the owners, but only at the cost of increased dispersion of the outcomes" (1958, p. 262); "any gains from using more of what might seem to be cheaper debt capital would thus be offset by correspondingly higher cost of the now riskier equity capital” (Miller, 1988, p. 100).

Chang (2015, pp. 50-51) has shown the following example (with $r=0.25)$ :

(I).

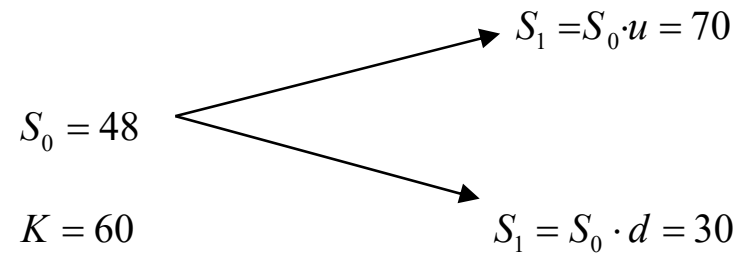

$$
\begin{cases}\text { Money Market : } & 1=\frac{1}{1+0.25}\left(\frac{3}{4} \times 1.25+\frac{1}{4} \times 1.25\right) \\ \text { Stock : } & S_{0}=48=\frac{1}{1+0.25}\left(\frac{3}{4} \times 70+\frac{1}{4} \times 30\right) \\ \text { Call Option: } & C=6=\frac{1}{1+0.25}\left(\frac{3}{4} \times 10+\frac{1}{4} \times 0\right) \\ \text { Put Option : } & P=6=\frac{1}{1+0.25}\left(\frac{3}{4} \times 0+\frac{1}{4} \times 30\right)\end{cases}
$$

(II).

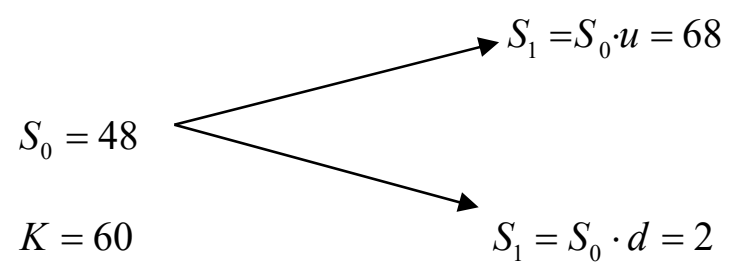

$$
\begin{cases}\text { Money Market : } & 1=\frac{1}{1+0.25}\left(\frac{58}{66} \times 1.25+\frac{8}{66} \times 1.25\right) \\ \text { Stock : } & S_{0}=48=\frac{1}{1+0.25}\left(\frac{58}{66} \times 68+\frac{8}{66} \times 2\right) \\ \text { Call Option : } & C=5.62424=\frac{1}{1+0.25}\left(\frac{58}{66} \times 8+\frac{8}{66} \times 0\right) \\ \text { Put Option : } & P=5.62424=\frac{1}{1+0.25}\left(\frac{58}{66} \times 0+\frac{8}{66} \times 58\right)\end{cases}
$$


(III).

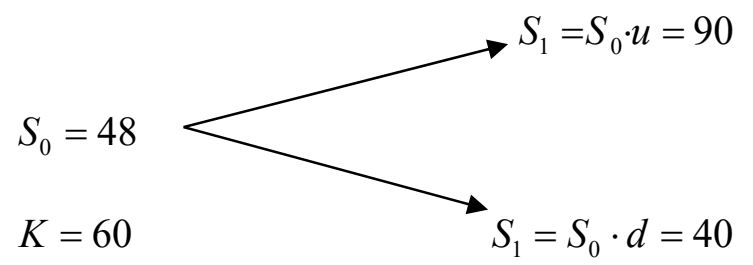

$$
\begin{cases}\text { Money Market : } & 1=\frac{1}{1+0.25}\left(\frac{2}{5} \times 1.25+\frac{3}{5} \times 1.25\right) \\ \text { Stock : } & S_{0}=48=\frac{1}{1+0.25}\left(\frac{2}{5} \times 90+\frac{3}{5} \times 40\right) \\ \text { Call Option : } & C=9.6=\frac{1}{1+0.25}\left(\frac{2}{5} \times 30+\frac{3}{5} \times 0\right) \\ \text { Put Option : } & P=9.6=\frac{1}{1+0.25}\left(\frac{2}{5} \times 0+\frac{3}{5} \times 20\right)\end{cases}
$$

We can find that the range of the stock price $S_{0}$ in (II) is larger than that in (I), and (II)'s call and put prices are lower. The range of the stock price in (III) is also larger than that in (I), but (III)'s call and put prices are higher. Using the actual probabilities $p$ and $1-p$, we can calculate the variances of the underlying asset price:

$$
\begin{aligned}
& \text { For (I), } \sigma_{1}^{2}=\frac{3}{4} \cdot(70-60)^{2}+\frac{1}{4} \cdot(30-60)^{2}=300 . \\
& \text { For (II), } \sigma_{2}^{2}=\frac{58}{66} \cdot(68-60)^{2}+\frac{8}{66} \cdot(2-60)^{2}=464 \\
& \text { For (III), } \sigma_{3}^{2}=\frac{2}{5} \cdot(90-60)^{2}+\frac{3}{5} \cdot(40-60)^{2}=600 .
\end{aligned}
$$

The variance of the stock price in (II) is larger than that in (I), and (II)'s call and put prices are lower. The variance of the stock price in (III) is also larger than that in (I), but (III)'s call and put prices are higher. These results are different from the Black-Scholes-Merton option pricing model's $\frac{\Delta c}{\Delta \sigma}=\frac{\Delta p}{\Delta \sigma}>0$, where $\sigma$ is the volatility. ${ }^{10}$

\footnotetext{
${ }^{10}$ Ross (1993, p. 470) and Chang (2014) have shown that with complete market, no transaction costs and no arbitrage, the Black-Scholes-Merton option pricing model has the restriction: $r=\mu+\frac{1}{2} \sigma^{2}$.
} 


\section{Concluding Remarks}

This paper has used the Arbitrage Theorem under binomial case to show that in a complete market with no transaction costs and no arbitrage, for any asset, the current spot price is a function of the risk-free interest rate, the future possible prices and their probabilities. Once the risk-free interest rate, the current spot price, and the future possible prices are assumed, the probabilities will be determined. These probabilities are actually the real world probabilities, not the so-called risk-neutral probabilities. The paper also proves that for the levered firm, (i) under riskless debt, increasing the debt-equity ratio increases the variance of the rate of return on equity and has no effect on the rate of return on debt; and (ii) under risky debt, increasing the debt-equity ratio increases the variance of the rate of return on debt but does not affect the probability density function of the rate of return on equity. With the actual world probabilities, it can be shown that changes in the debt-equity ratio do not affect the expected rate of return on the equity of the levered firm. These findings refute the Modigliani-Miller second proposition that the expected rate of return on the equity of the levered firm increases in proportion to the debt-equity ratio. With the actual world probabilities, it is also found that increasing the variance of the underlying asset price may either increase or decrease the option prices. 


\section{REFERENCES}

Black, Fischer and Myron Scholes, 1973, “The Pricing of Options and Corporate Liabilities," Journal of Political Economy 81, 637-654.

Brealey, Richard, Myers, Stewart and Allen, Franklin, 2017, Principles of Corporate Finance, McGraw-Hill, New York.

Chang, Kuo-Ping, 2016, "The Modigliani-Miller Second Proposition Is Dead; Long Live the Second Proposition,” Ekonomicko-manažerské Spektrum 10, 24-31; http://ssrn.com/abstract=2762158.

Chang, Kuo-Ping, 2015, The Ownership of the Firm, Corporate Finance, and Derivatives: Some Critical Thinking, Springer, New York.

Chang, Kuo-Ping, 2014, "Some Misconceptions in Derivative Pricing," http://ssrn.com/abstract=2138357.

Cox, John, Stephen Ross, and Mark Rubinstein, 1979, “Option Pricing: A Simplified Approach,” Journal of Financial Economics 7, 229-263.

Miller, Merton, 1988, “The Modigliani-Miller Propositions: After Thirty Years,” Journal of Economic Perspectives 2, 99-120.

Modigliani, Franco and Miller, Merton, 1958, "The Cost of Capital, Corporation Finance and the Theory of Investment," American Economics Review 48, 261-297.

Ross, Sheldon, 1993, Introduction to Probability Models, Academic Press, New York.

Ross, Stephen, Westerfield, Randolph, Jaffe, Jeffrey and Jordan, Bradford, 2016, Corporate Finance, McGraw-Hill, New York. 
Ross, Stephen, 1998, “The Mathematics of Finance: Pricing Derivatives," Quarterly of Applied Mathematics 56, 695-706.

Wilmott, Paul, 2007, Paul Wilmott Introduces Quantitative Finance, John Wiley \& Sons, West Sussex, England. 


\begin{abstract}
APPENDIX
Wilmott (2007, p. 77) argues: Assume: “(1) two stocks A and B; (2) both have the same value, same volatility and are denominated in the same currency; (3) both have call options with the same strike and expiration; (4) stock A is doubling in value every year, stock B is halving. Therefore both call options have the same value. But which will you buy? That one stock is doubling and the other halving is irrelevant. That option prices don't depend on the direction that the stock is going can be difficult to accept initially".

Ross (1998, p. 701) argues: "Take two stocks that both follow binomial processes and that are not perfectly correlated. Further, suppose that the stocks differ only in that one has a much higher probability of an up jump than does the other. If our analysis is to be believed, then when the stock prices of each are equal the two option values will be equal! How can this be? How can the value of an option on a stock be independent of the probability that the stock will go up?".

Both Wilmott's and Ross' arguments are erroneous because the assumptions they made contradict each other. For Wilmott's, the second assumption contradicts the fourth one: if stock A is doubling in value every year and stock B is halving, it is impossible that now the two stocks can have the same value, i.e., stock A must have higher value than stock B. For Ross' assumptions, if one stock has a much higher probability of an up jump than does the other, the two stock prices cannot be equal, i.e., the one with higher probability of an up jump must be more expensive than another one.
\end{abstract}

